\title{
Calcium Kinetics in the Hyperprostaglandin E Syndrome
}

\author{
LAWRENCE SHOEMAKER, THOMAS R. WELCH, WILLIAM BERGSTROM, STEVEN A. ABRAMS, \\ ALFRED L. YERGEY, AND NANCY VIEIRA \\ Departments of Pediatrics, University of Cincinnati College of Medicine, Cincinnati, Ohio 45229 [L.S., T.R.W.] \\ SUNY Health Science Center, Syracuse, New York 13210 [W.B.]; and Baylor College of Medicine, Houston, \\ Texas 77030 [S.A.A.]; the Division of Nephrology, Children's Hospital Research Foundation [L.S., T.R.W.]; \\ Children's Nutrition Research Center, Cincinnati, Ohio [S.A.A.]; and the Laboratory of Theoretical and Physical \\ Biology, National Institutes of Health, Bethesda, Maryland 20892 [A.L.Y.]
}

\begin{abstract}
Metabolic investigations, including the use of stable isotopes of calcium, were used to study calcium kinetics in three children with the hyperprostaglandin $\mathbf{E}$ syndrome. The studies were performed both during indomethacin treatment and in the absence of therapy. Off therapy, each child had hypercalciuria (mean urinary calcium excretion $0.478 \mathrm{mM} / \mathrm{kg} / \mathrm{d}$ ), hyperprostaglandinuria, and elevated serum calcitriol concentration. All had diminished bone density and were euparathyroid. Indomethacin treatment was associated with a marked reduction in serum calcitriol concentration, as well as decreased prostaglandin E excretion. Mean urinary calcium excretion fell to 0.135 $\mathrm{mM} / \mathrm{kg} / \mathrm{d}$. The stable isotope studies defined two components to the hypercalciuria of this disease: an indomethacin-sensitive dietary contribution and a relatively indomethacin-resistant bone resorptive element. Bone densitometry confirmed the presence of the resorptive element by demonstrating skeletal demineralization. (Pediatr Res 33: 92-96, 1993)
\end{abstract}

\section{Abbreviations}

iPTH, intact parathyroid hormone

$\mathrm{PGE}_{2}$, prostaglandin $\mathrm{E}_{2}$

Va, calcium absorption

Vou, component of 24-h urinary calcium excretion derived from recent diet

Vi, calcium intake

$\mathrm{Vu}, 24-\mathrm{h}$ urinary calcium excretion

Vbu, endogenous, or tissue-derived, component of total 24$h$ urinary calcium excretion

Elevation in urinary calcium excretion in childhood can be modest, as is often seen with idiopathic hypercalciuria, or extreme, as is seen in a variety of systemic disorders. Among the latter are Bartter's syndrome and its variants, which share several laboratory features including hypokalemia, hyperprostaglandinuria, and subnormal fractional distal chloride reabsorption under conditions of hypotonic diuresis $(1,2)$. In 1985, Seyberth et al. (3) described a distinct congenital hyperprostaglandinuric tubular syndrome with massive hypercalciuria that resembled

Received May 19, 1992; accepted September 14, 1992.

Correspondence and address reprints: Thomas R. Welch, M.D., Children's Hospital Medical Center, Division of Nephrology, Elland and Bethesda Ave., Cincinnati, OH 45229-2899.

Supported in part by Grant 00123 from the General Clinical Research Centers Branch, USPH, and by a grant from the March of Dimes Birth Defects Foundation (T.R.W.).
Bartter's syndrome, but differed in that the children demonstrated normal fractional distal chloride reabsorption and each had had a history of premature labor and polyhydramnios. Previously, a 6-y-old child diagnosed with severe idiopathic hypercalciuria had been described with features of the hyperprostaglandin E syndrome (4). Unlike the children reported by Seyberth et al., this child lacked evidence of an abnormality in potassium regulation. Although elevated plasma renin activity and aldosterone concentrations have been reported consistently in these patients, these findings are generally considered a consequence of renal prostaglandin synthesis, because they respond to therapy aimed at reducing this $(3-11)$.

In children with these hyperprostaglandinuric syndromes, therapy with the cyclooxygenase inhibitor, indomethacin, favorably affects most of the clinical and the biochemical abnormalities $(3-8,12-19)$. In some patients with massive hypercalciuria and nephrocalcinosis, however, the reduction in the urinary calcium excretion by this therapy is incomplete $(3,5,6,12,13)$. The facts that marked hypercalciuria persists for years in these children despite maximal dosages of indomethacin, but not in others on therapy with similar degrees of nephrocalcinosis (20), suggests that the hypercalciuria does not reflect dissolution of the calcinosis, but rather continued calcium excretion by established or alternative mechanisms. Such severe hypercalciuria places these children at risk of developing progressive nephrocalcinosis and renal failure $(21,22)$. To treat this disorder more effectively, it is necessary to understand the mechanisms mediating the excessive calcium loss.

A previous analysis of calcium balance, using ${ }^{47} \mathrm{Ca}$, concluded that three out of the four children with this disorder were in positive calcium balance (22). This is in agreement with more recent studies that suggested excessive enteric calcium absorption contributed to the hypercalciuria $(4,6)$. Most reports, however, have implicated a primary renal reabsorptive defect $(4,22,23)$. To investigate this problem further, we used a recently developed technique employing stable isotopes to measure calcium absorption and to determine the component of urinary calcium excretion derived directly from the diet. This was performed in three boys with massive hypercalciuria, hyperprostaglandinuria, and nephrocalcinosis, both on and off therapy with indomethacin.

\section{MATERIALS AND METHODS}

Patients. The patients are followed at Children's Hospital Medical Center, Cincinnati, $\mathrm{OH}$, and State University of New York Health Sciences Center, Syracuse, NY. Each has polyuria, a urine concentrating defect, hypercalciuria, hyperprostaglandinuria, and nephrocalcinosis. The hypercalciuria partially but incompletely resolves with maximally tolerated dosages of in- 
domethacin. Patients 1 and 2 were included in a previous study from this laboratory, and their clinical features are detailed in that report (6). Patient 3 was recently investigated at age $4 \% / 12$ y for polyuria, polydipsia, and nephrocalcinosis. During hypotonic saline diuresis, his fractional distal tubular chloride reabsorption, calculated at the moment of maximal free water clearance $(24$, 25 ), was $81 \%$. He had a normal physical examination, plasma renin activity, and serum concentrations of electrolytes and aldosterone.

Three healthy children, ages 5.4 to 7.9 years, underwent the stable isotope protocol at USDA/ARS Children's Nutritional Research Center, Baylor College of Medicine, Houston, Texas. These children, who represent the age-matched control population for the stable isotope studies, had normal values for serum calcium, phosphate, albumin, creatinine, and alkaline phosphatase activity.

Informed consent was obtained from the parents of every child, and the investigational protocol was reviewed and approved by the respective institutional review boards.

Protocol. Sterile solutions of the chloride salts of ${ }^{42} \mathrm{Ca},{ }^{44} \mathrm{Ca}$, and ${ }^{46} \mathrm{Ca}$ were prepared by the National Institutes of Health pharmacy and tested for pyrogenicity and sterility before use. Calcium isotopes were obtained from Oak Ridge National Laboratory, Oak Ridge, TN.

Each patient was studied both off and on indomethacin. The drug was administered every $8 \mathrm{~h}$ at the largest dose tolerated without adverse gastrointestinal symptoms (range: $2.4-5.0 \mathrm{mg} /$ $\mathrm{kg} / \mathrm{d}$ ). Studies were performed in patient 3 prior to beginning indomethacin therapy; in the other patients, the initial studies were performed 72-96 $\mathrm{h}$ after the last dose of indomethacin. Our experience and that of others $(3,13,26)$ suggest that this is an adequate washout period, since symptoms recurred in all patients, and it is consistent with the drug's $t_{1 / 2}$ of $4-5 \mathrm{~h}$. The children were given only water and indomethacin (when indicated) after the evening meal. $12.5 \mathrm{mM} / \mathrm{kg}$ of ${ }^{44} \mathrm{Ca}$ was allowed to equilibrate in 8 ounces of milk overnight. After the first morning urine was collected, blood was drawn by venipuncture for measurement of iPTH and vitamin D metabolites, and 2.5 $\mathrm{mM} / \mathrm{kg}^{42} \mathrm{Ca}$, diluted to $10 \mathrm{~mL}$ in half isotonic saline, was infused slowly. This was followed by breakfast, during which the isotopeequilibrated milk was drunk. The milk cartons were rinsed twice with water, and the the water was also drunk. Urine was collected for $24 \mathrm{~h}$, and dietary assessment of 24-h calcium intake was performed from nursing and parental records by a staff dietitian. In the control subjects, an identical protocol was performed except that ${ }^{46} \mathrm{Ca}$ was used as the oral tracer.

Analytical methods. Aliquots from the 24-h urine collections were analyzed at the National Institutes of Health or at Baylor College of Medicine, where the enrichment of ${ }^{42} \mathrm{Ca}$ and ${ }^{44} \mathrm{Ca}$ (or ${ }^{46} \mathrm{Ca}$ in control children) relative to ${ }^{48} \mathrm{Ca}\left({ }^{43} \mathrm{Ca}\right.$ in controls) was determined by thermal ionization mass spectrometry. This was used to calculate the fractional absorption of calcium and the fraction of each dose of isotope excreted in the urine (27). These values allow the determination of $\mathrm{Va}$ and the component of the urinary Vou directly derived from the diet:

\section{$\mathrm{Va}=\mathrm{Vi} \times$ fractional absorption of calcium}

$\mathrm{Vou}=\mathrm{Vi} \times$ fraction of oral isotope excreted in urine

Urine calcium concentration was measured by flame atomic absorption spectrophotometry and was used to determine $\mathrm{Vu}$. $\mathrm{Vbu}$ is the difference between Vou and Vu. For paired data, $t$ test was used to analyze the response of these parameters to therapy.

Serum and urine electrolytes, calcium, phosphate, creatinine, and complete blood counts were measured in the clinical laboratory. Urine concentrations of $\mathrm{CAMP}$ and $\mathrm{PGE}_{2}$ were measured as previously described (6).

Vitamin D metabolites were extracted from serum by solidphase extraction cartridges, and the calcitriol concentration was measured by a competitive radioligand assay described previously (28). Coefficients of variance are $5.2 \%$ intraassay and $6.4 \%$ interassay.

Serum PTH concentration was determined by a two-site immunoradiometric assay (29). This assay measures the intact PTH molecule and has a sensitivity of $1 \mathrm{pg} / \mathrm{mL}(0.1053 \mathrm{pmol} / \mathrm{L})$. Intra- and interassay coefficients of variance are 4 and $8 \%$, respectively (Allegro Intact PTH Immunoassay, Nichols Institute, San Juan Capistrano, CA).

Bone mineral content and bone width were determined by $\mathrm{x}$ ray densitometry in patient 2 and by single-beam photon absorptiometry in patients 1 and 3. Measurements were taken from the left radius at the "midshaft" site, which is actually one-third the length between the ulnar styloid and the olecranon. These measurements were performed using a Hologic QDR-1000/W wholebody x-ray bone densitometer (Hologic Inc., Waltham, MA) in patient 2, and with a Lunar Bone Mineral Analyzer (Lunar Radiation Inc., Madison, WI) in patients 1 and 3. Bone mineral content:bone width ratios were compared with age, gender, and race-specific normal values (30) for the photon absorptiometry measurements and with an age-matched population of 13 normal children for the $\mathrm{x}$-ray densitometry determinations (Bonny Specker, Ph.D., personal communication).

\section{RESULTS}

Calcium metabolism. Every patient was normocalcemic and hypercalciuric $(\mathrm{Vu}>0.1 \mathrm{mM} / \mathrm{kg} / \mathrm{d}$ ) both off and on cyclooxygenase inhibitor therapy (Table 1). Serum phosphate concentration was normal in patient 1 and mildly low in patient 3 , whether or not indomethacin was taken. PTH concentrations were normal in each child not receiving indomethacin. Both phosphate and PTH concentrations were normal off therapy and slightly elevated during therapy in patient 2, probably because of renal insufficiency. Serum calcium concentrations decreased in each patient with therapy; ionized calcium concentrations were not obtained, but this was probably low in patient 2 during therapy, since his severe concentrating defect and alkalosis was refractory to indomethacin. $\mathrm{Tm}_{\mathrm{PO}} / \mathrm{GFR}$ was normal in patient 1 and reduced in patient 3 ; in neither child was the ratio appreciably affected by indomethacin. During therapy, this value rose to normal in patient 2. Urine cAMP was measured in patient 3 to assess renal PTH activity. The urine cAMP/creatinine ratios, off and on indomethacin respectively, were 10.3 and $9.3 \mathrm{nM} / \mathrm{mg}$. The range of normal ratios, ( $2 \mathrm{SD}$ below and above the mean) are $5.0-15.0 \mathrm{nM} / \mathrm{mg}$.

Serum concentrations of calcitriol were elevated in every child off indomethacin (Table 1). These values returned to normal during therapy in patients 1 and 3 ; in patient 2 , the calcitriol concentration decreased nearly $50 \%$ but remained slightly elevated. Similarly, each child off therapy was hyperprostaglandinuric, with $\mathrm{PGE}_{2}$ excretion exceeding the upper limit of 0.154 $\mathrm{mM} / \mathrm{h} / 1.73 \mathrm{~m}^{2}$ (2 SD above mean of normals) (6). Urine $\mathrm{PGE}_{2}$ excretion, as measured by $\mathrm{PGE}_{2} /$ creatinine ratios, decreased with therapy in each patient, returning to normal in patients 1 and 2 . Indomethacin was associated with a rise in the osmolality of the first morning urines and with a decrease in creatinine clearance in each child.

Except for patient 3, who had a calcium-rich diet, Vi was comparable with the age-matched controls (Table 2). Va was increased to approximately twice the control value; whereas $\mathrm{Vu}$, Vou, and Vbu were much more elevated in the patients than in the controls. Indomethacin was associated with an over $50 \%$ reduction in Vou in all ( $p=0.01$ by paired $t$ test), similar to the reduction in serum concentration of calcitriol. There was a less dramatic decline in $\mathrm{Va}$ and $\mathrm{Vu}$ with therapy. In contrast, the effect of therapy on Vbu was variable: in two patients, it decreased approximately 33\%; in the other, it increased. The response of $\mathrm{Va}, \mathrm{Vu}$, and $\mathrm{Vbu}$ to therapy failed to achieve statistical significance. 
Table 1. Metabolic studies in three hypercalcemic children, off and on indomethacin therapy

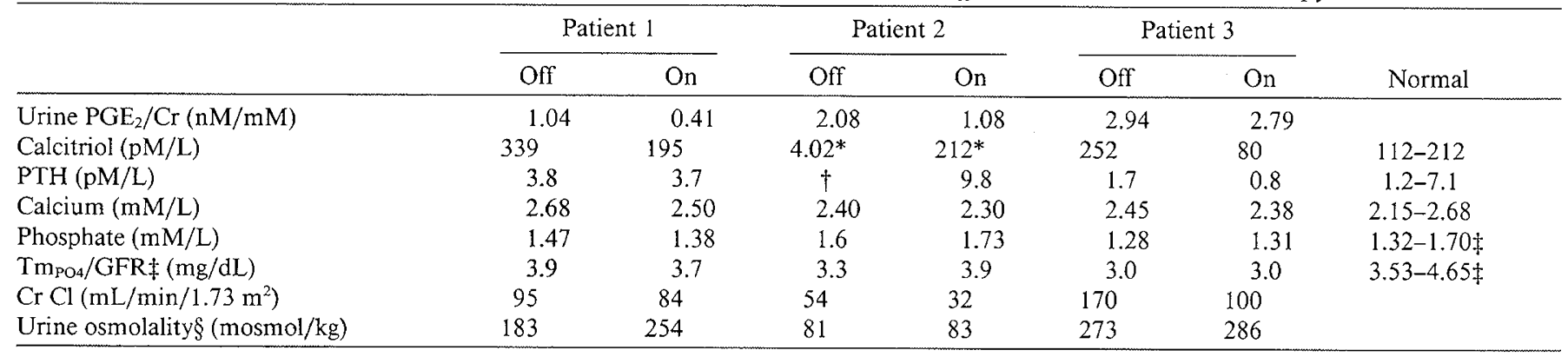

* Calcitriol concentrations in sera from patient 2 were performed by Endocrine Sciences (Calabasas Hills, CA). Normal values reported from an adult population by this laboratory range $52-120 \mathrm{pM} / \mathrm{L}$.

$\uparrow$ Serum PTH concentration when patient 2 was off indomethacin was performed by SmithKline and Beacham Laboratories (Van Nuys, CA). Both carboxy-terminal and midmolecule measurements were normal.

+ Brodehl et al. (45), fasting norms.

$\S$ Samples were obtained from the first morning void.

Table 2. Stable calcium isotope studies in three patients and age-matched healthy children off and on indomethacin therapy*

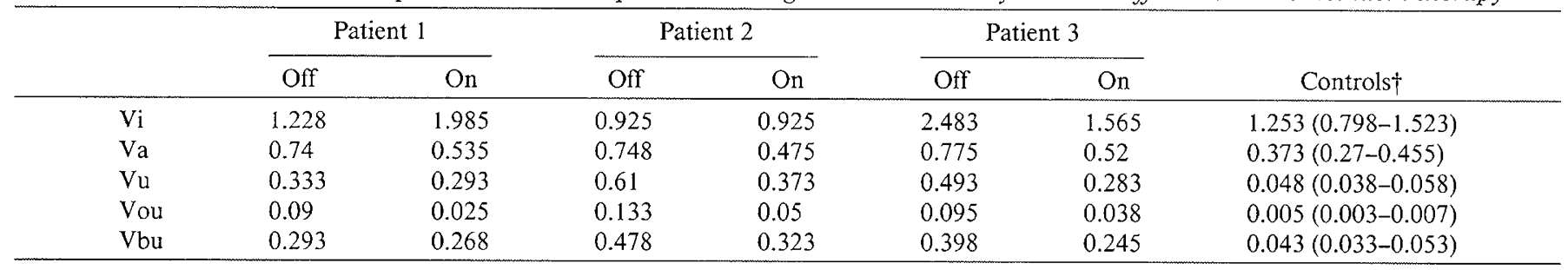

* All values are in $\mathrm{mM} / \mathrm{kg} / \mathrm{d}$.

$\dagger$ Mean (range).

Bone density and growth. The $\mathrm{BMC} / \mathrm{BW}$ ratio was low in each child, ranging from $67.6-84.5 \%$ of the mean values of control children (Table 3 ). In contrast, only the eldest boy was less than the fifth percentile in height. Patients 1 and 2 were each below the fifth percentile when initially evaluated; the height of patient 3 was at the the 50th percentile. The linear growth velocities of patients 1 and 2 increased from below the 3 rd percentile during the 6-mo interval preceding indomethacin therapy to above the 97 th percentile during the initial 6 mo with this therapy. In contrast, there was no significant change in the growth velocity of patient 3 , which remained at approximately the 50 th percentile. Skeletal radiographs did not reveal rickets or hyperparathyroidism; either initially or after therapy with indomethacin had been undertaken.

\section{DISCUSSION}

Royer et al. (31) were the first to report hypercalciuria in some patients with chronic idiopathic hyperkaliuric hypokalemia, a congenital electrolyte disorder initially described by Rosenbaum and Hughes (32). Several reports soon followed, confirming the findings of hypercalciuria and nephrocalcinosis in a subset of these patients $(5,22,23)$. Previously, Arant et al. (21) had described two patients with a similar electrolyte disorder who developed interstitial nephritis and terminal renal failure; nephrocalcinosis was evident in one patient, although urinary Vou was never measured.

Table 3. Bone density results in three hypercalciuric children

\begin{tabular}{ccccc}
\hline Patient & $\begin{array}{c}\text { Age } \\
(\mathrm{y})\end{array}$ & $\begin{array}{c}\mathrm{Wt} \\
(\mathrm{kg})\end{array}$ & $\begin{array}{c}\mathrm{Ht} * \\
(\mathrm{~cm})\end{array}$ & $\begin{array}{c}\mathrm{BMC} / \mathrm{BW} \dagger \\
\left(\mathrm{gm} / \mathrm{cm}^{2}\right)\end{array}$ \\
\hline 1 & 4.2 & 16.5 & $100.2,(25)$ & $0.262,(78.7)$ \\
2 & 7.8 & 18.9 & $113.0,(<5)$ & $0.376,(84.5)$ \\
3 & 4.8 & 18.5 & $109.3,(50)$ & $0.225,(67.6)$ \\
\hline
\end{tabular}

* Numbers in parentheses are percentiles.

$\uparrow$ Numbers in parentheses are percentages of mean $\mathrm{BMC} / \mathrm{BW}$ in matched, normal children.
The therapy of hypercalciuria in this disease has not been satisfactory. Diuretics $(4,5,12,22,23)$, modification of dietary sodium (22) or calcium $(3-5,22)$, oral phosphate $(22,23)$, prednisolone (3), and calcitonin have either been unsuccessful or associated with unacceptable complications.

Recognition of hyperprostaglandinuria in this syndrome led to attempts at treatment with cyclooxygenase inhibitors. Such treatment usually corrected polyuria and electrolyte disorders; its effect on calciuria, however, was less uniform (3-9, 12-14, 33 ). Over the long term, hypercalciuria is associated with progressive nephrocalcinosis and renal insufficiency. Thus, there is a critical need to establish an effective therapy. Before such therapy can be designed, however, a better understanding of the mechanisms of hypercalciuria is clearly needed.

We have used a new technique to quantitate the proportion of urinary calcium excretion derived from recent diet and that which is mobilized from tissue stores, presumably bone. Our results confirmed previous suggestions by us (6) and others (4, 22) that enhanced enteric calcium absorption contributed to hypercalciuria, and that this component was sensitive to indomethacin therapy. The enhanced enteric absorption correlated with elevated serum concentrations of calcitriol, which also decreased with cyclooxygenase inhibitor therapy. This is similar to a study in which either aspirin or indomethacin therapy decreased calcitriol concentrations and reduced the incremental calciuric response to an oral calcium load (4).

Although indomethacin therapy reduced both total $(\mathrm{Vu})$ and recent diet-derived (Vou) urinary calcium excretion, calciuria continued to be well above normal in all. The balance of the urine calcium must have been mobilized from tissue stores, largely bone. The presence of skeletal hypomineralization in all three children supports this conclusion. The cause of the increased bone turnover is unclear, although several possibilities can be excluded by our data.

Increased serum concentrations of calcitriol may exert a calcium-mobilizing effect on bone. Although all patients had elevated serum calcitriol levels in the absence of treatment, these 
values normalized on indomethacin. Despite a significant reduction in the absorptive component of calcium excretion, massive hypercalciuria persisted.

Hyperparathyroidism is another potential cause of increased bone turnover in these children. Leonhardt and coworkers (26) found mean levels of iPTH elevated in a group of nine children with this syndrome while receiving indomethacin. Their patients, however, had a substantial degree of renal insufficiency with therapy [creatinine clearances ranging from 37-95 (median 54) $\mathrm{mL} / \mathrm{min} / 1.73 \mathrm{~m}^{2}$ ], making interpretation of their parathyroid status problematic. Our patients were euparathyroid, as evidenced by a highly specific two-site radioimmunoassay $(29,34-$ 36). Similarly, patients with this disease and normal renal function reported by Ohlsson et al. (37) and Kohout and Bachmann (14) also had normal serum PTH concentrations.

The $\mathrm{Tm}_{\mathrm{PO} 4} / \mathrm{GFR}$ ratios are not consistent with PTH-related peptide activity $(38,39)$. Although $\mathrm{Tm}_{\mathrm{PO} 4} / \mathrm{GFR}$ was slightly diminished in patient 3, PTH-related peptide activity is not likely because he was subsequently shown to have normal urinary cAMP excretion. The mildly reduced $\mathrm{Tm}_{\mathrm{PO} 4} / \mathrm{GFR}$ values may represent an additional feature of the calcium metabolic derangement that prevents hyperphosphatemia, a common feature of resorptive hypercalciuria (40).

The absence of hyperparathyroidism also excludes a "renal leak" of calcium as a primary disturbance, with tissue calcium mobilization a secondary phenomenon. Such a mechanism requires a secondary increase in PTH (41) and would be expected to result in calcipenic rickets (42) if enteric absorption were unable to compensate for the excessive calciuria. Rickets is rarely observed in these hypercalciuric children, however, unless additional tubular defects are involved or renal insufficiency supervenes $(3,5,6,21,22)$.

Hypercalciuria has also been described as a consequence of a primary phosphate leak in two familial syndromes with differing modes of inheritance $(43,44)$. Each is characterized by normal or suppressed PTH concentrations and elevated concentrations of calcitriol. Hypophosphatemia is an invariable feature which distinguishes these patients from ours.

Seyberth et al. $(3,26)$ have speculated that increased bone resorption, probably mediated by $\mathrm{PGE}_{2}$, contributed to hypercalciuria. Although we believe that this is likely, other mediators may also be involved. Because $\mathrm{PGE}_{2}$ excretion was normalized in two patients during therapy, it is unlikely that excessive systemic prostanoid activity solely is responsible for increased bone turnover. Others have observed a lack of association between hypercalciuria and renal or systemic $\mathrm{PGE}_{2}$ hyperactivity (13). Our data clearly show that the predominant effect of indomethacin in this disease is on enteric calcium absorption.

In summary, the significant reduction in recent diet-derived calciuria, but not the tissue-derived component, supports the hypothesis that additional mediator(s) of bone resorption are active in children with this syndrome. More importantly, these findings suggest that indomethacin therapy may worsen the bone mineralization status if the calcitriol-stimulated absorption is a protective feature.

This novel methodology is useful in following response to therapy, and it is likely to be beneficial in promoting a better understanding of the various mechanisms of hypercalciuria. Such understanding may permit development of strategies to treat children with this heterogeneous disease. Additionally, they may be widely applicable in other hypercalciuric states.

Acknowledgments. The authors thank the skillful technical assistance of Diane Brockman, Rosa Sierra, and Esther Tombragel. Deborah Gregg, R.D., L.D., and Janice Stuff, M.S., R.D., provided expert nutritional services. We thank Cheryl Fryer, M.D., and Cajsa J. Schumacher, M.D., for allowing us to share in the medical care and evaluations of their patients. Bonny Specker, Ph.D., and George Hug, M.D., offered thoughtful advice, and Barbara Pieper provided expert secretarial support.
Also, we thank the families of both the patients and the control children for their time and effort that was necessary to complete these studies.

\section{REFERENCES}

1. Bartter FC, Pronove P, Gill JR, MacCardle RC, Diller E 1962 Hyperplasia of the juxtaglomerular complex with hyperaldosteronism and hypokalemic alkalosis: a new syndrome. Am J Med 33:811-828

2. Stein JH 1985 The pathogenetic spectrum of Bartter's syndrome. Kidney Int 28:85-93

3. Seyberth HW, Rascher W, Schweer H, Kühl PG, Mehis O, Scharer K 1985 Congenital hypokalemia with hypercalciuria in preterm infants: a hyperprostaglandinuric tubular syndrome different from Bartter syndrome. $J$ Pediatr 107:694-701

4. Houser M, Zimmerman B, Davidman M, Smith C, Sinaiko A, Fish A 1984 Idiopathic hypercalciuria associated with hyperreninemia and high urinary prostaglandin E. Kidney Int 26:176-182

5. Dillon MJ, Shah V, Mitchell MD 1979 Bartter's syndrome: 10 cases in childhood. Results of long-term indomethacin therapy. Q J Med 48:429446

6. de Rovetto CR, Welch TR, Hug G, Clark KE, Bergstrom W 1989 Hypercalciuria with Bartter syndrome: evidence for an abnormality of vitamin D metabolism. J Pediatr 115:397-404

7. Fichman MP, Telfer N, Zia P, Speckart P, Golub M, Rude R 1976 Role of prostaglandins in the pathogenesis of Bartter's syndrome. Am J Med 60:785797

8. Gill JR, Frölich JC, Bowden RE, Taylor AA, Keiser HR, Seyberth HW, Oates JA, Bartter FC 1976 Bartter's syndrome: a disorder characterized by high urinary prostaglandins and a dependence of hyperreninemia on prostaglandin synthesis. Am J Med 61:43-51

9. Verberckmoes R, van Damme B, Clement J, Amery A, Michielsen P 1976 Bartter's syndrome with hyperplasia of renomedullary cells: successful treatment with indomethacin. Kidney Int 9:302-307

10. Gerber JG, Olson RD, Nies AS 1981 Interrelationship between prostaglandins and renin release. Kidney Int 19:816-821

11. Henrich WL 1981 Role of prostaglandins in renin secretion. Kidney Int 19:822-830

12. Proesmans W, Massa G, Vanderschueren-Lodeweyckx M 1988 Growth from birth to adulthood in a patient with the neonatal form of Bartter syndrome. Pediatr Nephrol 2:205-209

13. Seyberth HW, Koniger SJ, Rascher W, Kuhl PG, Schweer H 1987 Role of prostaglandins in hyperprostaglandin $\mathrm{E}$ syndrome and in selected renal tubular disorders. Pediatr Nephrol 1:491-497

14. Kohout I, Bachmann H 1987 Different types of idiopathic hypercalciuria in children. Monatsschr Kinderheilkd 135:847-850

15. Proesmans W, Muaka BK, Monnens L 1977 Indomethacin therapy in Bartter syndrome. Acta Paediatr Belg 30:31-36

16. Littlewood JM, Lee MR, Meadow SR 1978 Treatment of Bartter's syndrome in early childhood with prostaglandin synthetase inhibitors. Arch Dis Child 53:43-48

17. Lechacz G, Arbus GS, Balfe JW, Wolff ED, Robson L 1979 Effect of ibuprofen on growth in a child with Bartter syndrome. J Pediatr 95:319-320

18. Floret D, David M, Roux A, Hage G-N, Teyssier G 1979 Bartter's syndrome: the long term effects of indomethacin on growth. Nouv Presse Med 8:17-21

19. Norby L, Flamenbaum W, Lentz R, Ramwell P 1976 Prostaglandins and aspirin therapy in Bartter's syndrome. Lancet ii:604-606

20. Matsumoto J, Han BK, de Rovetto CR, Welch TR 1989 Hypercalciuric Bartter Syndrome: resolution of nephrocalcinosis with indomethacin. AJR 152:1251-1253

21. Arant BS, Brackett NC, Young RB, Still WJS 1970 Case studies of sibling with juxtaglomerular hyperplasia and secondary aldosteronism associated with severe azotemia and renal rickets: Bartter's syndrome or disease? Pediatrics 46:344-361

22. McCredie DA, Rotenberg E, Williams AL 1974 Hypercalciuria in potassiumlosing nephropathy: a variant of Bartter's syndrome. Aust Paediatr J 10:286295

23. Fanconi A, Schachenmann G, Nüssli R, Prader A 1971 Chronic hypokalaemia with growth retardation, normotensive hyperrenin-hyperaldosteronism ("Bartter's syndrome"), and hypercalciuria: report of two cases with emphasis on natural history and on catch-up growth during treatment. Helv Paediatr Acta 2:144-163

24. Rodriguez-Soriano J, Vallo A, Castillo G, Oliveros R 1981 Renal handling of water and sodium in infancy and childhood: a study using clearance methods during hypotonic saline diuresis. Kidney Int 20:700-704

25. Gill JR Bartter FC 1978 Evidence for a prostaglandin-independent defect in chloride reabsorption in the loop of Henle as a proximal cause of Bartter's syndrome. Am J Med 65:766-772

26. Leonhardt A, Timmermanns G, Roth B, Seyberth HW 1992 Calcium homeostasis and hypercalciuria in hyperprostaglandin $E$ syndrome. $J$ Pediat 120:546-554

27. Hillman LS, Tack E, Covell DG, Vieira NE, Yergey AL 1988 Measurement of true calcium absorption in premature infants using intravenous ${ }^{46} \mathrm{Ca}$ and oral ${ }^{44} \mathrm{Ca}$. Pediatr Res 23:589-594

28. McGraw CA, Hug G 1990 Simultaneous measurement of 25-hydroxy, 24,25dihydroxy-, and 1,25-dihydroxyvitamin D without use of HPLC. Med Lab Sci 47:17-25 
29. Nussbaum SR, Zahradnik RJ, Lavigne JR, Brennan GL, Nozawa-Ung K, Kim LY, Keutmann HT, Wang C, Potts JT, Segre GV 1988 Highly sensitive twosite immunoradiometric assay of parathyrin, and its clinical utility in evaluating patients with hypercalcemia. Clin Chem 33:1364-1367

30. Li JY, Specker BL, Ho ML, Tsang RC 1989 Bone mineral content in black and white children 1 to 6 years of age: early appearance of race and sex differences. Am J Dis Child 143:1346-1349

31. Royer P, Delaitre R, Mathieu H, Gabilan JC, Raynaud C, Pasqualini JR, Debris P, Gerbeaux S, Habib R 1964 L'hypokaliemie chronique idiopathique avec hyperkaliurie de l'enfant. Rev. Franc. Et Clin Biol 9:61-87

32. Rosenbaum P, Hughes M 1957 Persistent, probably congenital, hypokalemic metabolic alkalosis with hyaline degeneration of renal tubules and normal urinary aldosterone. Am J Dis Child 94:560(abstr)

33. Bowden RE, Gill JR, Radfar N, Taylor AA, Keiser HR 1978 Prostaglandin synthetase inhibitors in Bartter's syndrome: effect on immunoreactive prostaglandin E excretion. JAMA 239:117-121

34. Newman DJ, Ashby JP 1988 Clinical and laboratory evaluation of a two-site immunoradiometric assay for intact parathyroid hormone. Ann Clin Biochem 25:654-660

35. Kruse K, Kracht U, Wohlfart K, Kruse U 1988 Intaktes Serum-Parathormon (PTH 1-84). Dtsch Med Wochenschr 113:283-288

36. Key LL, Thorne M, Pitzer B, Volberg F, Turner C 1990 Management of neonatal hyperparathyroidism with parathyroidectomy and autotransplantation. J Pediatr 116:923-926

37. Ohlsson A, Sieck U, Cumming W, Akhtar M, Serenius F 1984 A variant of Bartter's syndrome: Bartter's syndrome associated with hydramnios, pre- maturity, hypercalciuria, and nephrocalcinosis. Acta Paediatr Scand 73:868874

38. Stewart AF, Horst R, Deftos LJ, Cadman EC, Lang R, Broadus AE 1980 Biochemical evaluation of patients with cancer-associated hypercalcemia. $N$ Engl J Med 303:1377-1383

39. Broadus AE, Mangin M, Ikeda K, Insogna KL, Weir EC, Burtis WJ, Stewart AF 1988 Humoral hypercalcemia of cancer: identification of a novel parathyroid hormone-like peptide. N Eng J Med 319:556-563

40. Stewart AF, Adler M, Byers CM, Segre GV, Broadus AE 1982 Calcium homeostasis in immobilization: an example of resorptive hypercalciuria. $\mathrm{N}$ Engl J Med 306:1136-1140

41. Pak CYC, Galosy RA 1979 Fasting urinary calcium and adenosine $3^{\prime}, 5^{\prime}$ monophosphate: a discriminant analysis for the identification of renal and absorptive hypercalciurias. J Clin Endocrinol Metab 48:260-265

42. Scriver CR, Tenenhouse HS, Glorieux FH 1991 X-linked hypophosphatemia: an appreciation of a classic paper and a survey of progress since 1958 . Medicine 70:218-228

43. Tieder M, Modai D, Samuel R, Arie R, Halabe A, Bab I, Gabizon D, Liberman UA 1985 Hereditary hypophosphatemic rickets with hypercalciuria. N Engl J Med 312:611-617

44. Proesmans WC, Fabry G, Marchal GJ, Gillis PL, Bouillon R 1987 Autosomal dominant hypophosphatemia with elevated serum 1,25 dihydroxyvitamin $\mathrm{D}$ and hypercalciuria. Pediatr Nephrol 1:479-484

45. Brodehl J, Krause A, Hoyer PF 1988 Assessment of maximal tubular phosphate reabsorption: comparison of direct measurement with the nomogram of Bijvoet. Pediatr Nephrol 2:183-189 